Research Article

\title{
Factors contributing to safe appendectomy in presence of appendiceal mass
}

\author{
Rakesh Kumar Pandit1*, Uma Shankar Gupta², Vinay Kumar Jha3 ${ }^{3}$ Subhash Thapa Magar4
}

Janaki Medical College Teaching Hospital, Ramdaiya

1,2,3,4Department of Surgery, Janaki Medical College Teaching Hospital, Ramdaiya

\begin{abstract}
Background and Objectives: Early appendectomy in presence of appendiceal mass (AM) is controversial. We present the results of our experience that contribute to safe appendectomy in AM.

Material and Methods: A total of 135 patients who underwent early surgery in presence of AM were reviewed. The diagnosis of AM was made clinically, using abdominal ultrasound and/or intra-operatively. All surgeries were done by qualified surgeons with variable experiences.

Results: Mean operative day since onset of pain was $5.64 \pm 2.1$ (range: $3-15$ ) days. A hundred and twenty patients underwent appendectomy, 116 (96.7\%) of which was done within 7 days of pain. Two other patients operated on the $6^{\text {th }}$ day had only drainage of abscess and no appendectomy. Remaining 4 (3.3\%) appendectomies were performed on the $8^{\text {th }}$ day. Two other patients operated on the $8^{\text {th }}$ day had failed attempt of appendectomy and had just drainage of abscess. Two patients, operated on $12^{\text {th }}$ and $15^{\text {th }}$ day had just open-close. Both had given misleading history of duration of pain. Remaining 9 patients, from the $9^{\text {th }}$ day onward underwent only just drainage of abscess. Only significant complication was injury to ileum during early years of experience when appendectomy was attempted on the $10^{\text {th }}$ day. He fared well in two weeks.
\end{abstract}

Conclusion: With experience we have developed confidence that experience and clarity of safe time limit makes early appendectomy in AM predictably safe. Few other patients who present later and need surgical intervention may be more safely managed by limited procedure like drainage of abscess without precarious attempt of appendectomy.

Key words: Appendicitis, mass, appendectomy, patient safety

\section{INTRODUCTION}

Conventionally the standard treatment of an appendiceal mass (AM), which usually forms after 48-72 hours of acute appendicitis, is conservative [1]. The decision is based on the fact that nature has already localized the lesion and inadvertent surgery at this time is difficult, bloody and dangerous [2]. However, early surgical treatment remains a favored 
modality of treatment in some experienced hands [3,4]. So, optimum management of AM remains controversial [5-7]. Proponents of early surgery opine that earlier belief that adhesiolysis and dissection of appendix in the mass is more difficult and the bowel loops are more friable is not a valid argument to preclude early surgery $[4,8]$.

Contention to early surgical treatment is mainly related to operative difficulties and risk of injury to bowel [3, 8-10]. Inflammatory adhesion escalates with time and during the early period, adhesion is not severe enough to preclude safe dissection. However, safe timing is not clear. Additionally, early surgical treatment does not portray precise procedures which might mean simply drainage of abscess or even major procedure like right hemicolectomy [11]. So, if factors that contribute to safe appendectomy are better defined, blemishes related to EA could be minimized and its potential benefit can be rationally utilized. Little such type of studies exists.

\section{MATERIAL AND METHODS}

This is a retrospective and descriptive study conducted at Janaki Medical College Teaching Hospital, Janakpur, Nepal. Medical records of the patients who had emergency surgery between February 2010 and November 2016 after 3 days of onset of pain due to appendicitis were reviewed. Out of 236 patients, 135 with established diagnosis of AM, with or without abscess, were studied. The diagnosis of AM was made clinically in 82 (60.7\%), using abdominal ultrasound in 22 (16.3\%) and intra-operatively in31 (23\%) patients. The patients excluded were those withpain duration of more than 3 days but no mass intra-operatively (milder form of appendicitis) and others with inadequate information.

\section{Operative technique, postoperative management and follow up}

Operative procedure and postoperative management has been described in detail in a recently published article [12]. Only a brief note given here. All patients had open surgery. Site of incision was best determined by palpation of mass after anesthesia. Good exposure was censured by cutting the muscles whenever necessary. Because of likelihood of adhesion of peritoneum to the bowel, it had to be opened with due precaution. Blunt finger dissection around and into the mass often opened up abscess cavity when present.

After drainage of abscess, blunt finger dissection often discerned a plane between the inflamed appendix and the omentum or bowel. Ligating bits of mesoappendix close to appendix under vision maintained meticulous hemostasis and facilitated progressive dissection. At times when subserosal plane of appendix was entered, it was safer to proceed through this plane rather than dissecting close to the bowel. Gangrenous and perforated appendix was at times removed in pieces. The base of appendix was ensured after it was seen to funnel out in caecum. The base was ligated by number 0 silk or chromic catgut. The stump was never buried. When the appendix was perforated at the base and appeared to involve adjacent caecum, it was sutured with interrupted 2-0 chromic catgut taking relatively healthy caecum wall.

When the mass was densely organized and dissection appeared unsafe, search for appendix was withheld, and only abscess, 
when present, was drained. In a few late presenters with large abscess, extraperitoneal drainage was done without an attempt for appendectomy. Tube drain was placed in almost all patients with abscess and only a few selected ones without abscess.

Post-operatively all the patients were given IV ceftriaxone 1 gm 12 hourly and metronidazole $500 \mathrm{mg} 8$ hourly. They were switched to oral forms on first to third postoperative day and continued for total of about seven days. Oral intake was allowed after 12-36 hours. They were discharged after they tolerated oral feed and removal of drain. Suture was removed on the $7^{\text {th }}$ to $8^{\text {th }}$ day. At discharge and after suture removal, patients were given contact phone number and advised for visit if they develop any problem.

\section{Outcome analysis}

Postoperative results were classified into safe appendectomy and failed or no attempt of appendectomy. By safe appendectomy we imply simple appendectomy with drainage of abscess if present, without any bowel injury and no significant post-operative morbidity. Failed attempt of appendectomy included those cases where appendectomy was attempted but not accomplished either because of difficult dissection or injury to the bowel. When abscess was present it was drained. When abscess was also not present and the dissection was not feasible because of advanced adhesion, laparotomy was just closed which was designated open-close. When the abscess was relatively large and old, just extra-peritoneal abscess drainage (peritoneal cavity not opened) was done without an attempt of appendectomy. Other factors noted included timing of surgery since onset of pain, surgeon's experience, surgical technique, operative findings like abscess, gangrene, perforation, stump condition, wound infection rate and hospital stay. The data were analyzed using MS excel 2010. Mean, standard deviation and range were used to describe the results.

\section{RESULTS}

There were 70 male and 65 female patients. The mean age was $23.2 \pm 8.8$ (range: 6-48) years. Mean Duration of pain at presentation was $5 \pm 1.9$ (range $2-15$ ) days, and at surgery $5.64 \pm 2.1$ (range: 3-15) days. One hundred and seventeen $(86.7 \%)$ patients were operated within 24 hours and 18 (13.3\%) patients within 72 hours of presentation.

\section{Operative findings}

Seventy three (54.1\%) patients had Phlegmon (inflammatory mass without an abscess), and 62 (45.9\%) had associated abscess. Before 5 days of pain abscess was encountered in $17(25.4 \%)$ and from $6^{\text {th }}$ to $8^{\text {th }}$ day in $36(63.2 \%)$ patients. From 9th day onward, excluding two patients operated on the $12^{\text {th }}$ and $15^{\text {th }}$ day, all the 9 patients had abscess. Among patients with abscess 50 (80.6\%) patients had perforation and/or gangrene. Among the 120 patients who had appendectomy, 57 (47.5\%) patients had abscess. Out of these 57 patients 50 (89.5\%) patients had viable residual stump of appendix and 7 (10.5\%) patients had practically little residual stump left.

\section{Operative procedures}

Varieties of surgical procedures performed are depicted in the Table. Appendectomy was done only up to the eighth day following the onset of pain. During the first 5 days, 
appendectomy was accomplished in all the patients.

\begin{tabular}{|c|c|c|}
\hline \multicolumn{3}{|c|}{$\begin{array}{l}\text { Table: Surgical procedures stratified by } \\
\text { duration of pain by the time of surgery. }\end{array}$} \\
\hline $\begin{array}{l}\text { Duration } \\
\text { of pain } \\
\text { (days) }\end{array}$ & Procedure & $\begin{array}{l}\text { No. of } \\
\text { patients }\end{array}$ \\
\hline $3-5$ & Appendectomy & 67 \\
\hline \multirow[t]{2}{*}{6} & Appendectomy & 30 \\
\hline & Trans-peritoneal drainage & 2 \\
\hline 7 & Appendectomy & 19 \\
\hline \multirow[t]{2}{*}{8} & Appendectomy & 4 \\
\hline & Trans-peritoneal drainage & 2 \\
\hline \multirow[t]{2}{*}{9} & Trans-peritoneal drainage & 2 \\
\hline & $\begin{array}{l}\text { Extra-peritoneal abscess } \\
\text { drainage }\end{array}$ & 2 \\
\hline \multirow[t]{2}{*}{10} & Trans-peritoneal drainage & 1 \\
\hline & $\begin{array}{l}\text { Extra-peritoneal abscess } \\
\text { drainage }\end{array}$ & 2 \\
\hline \multirow[t]{2}{*}{12} & $\begin{array}{l}\text { Extra-peritoneal abscess } \\
\text { drainage }\end{array}$ & 2 \\
\hline & Open-close & 1 \\
\hline 15 & Open-close & 1 \\
\hline
\end{tabular}

On the sixth day 30 (93.75\%) patients had appendectomy. Two (6.25\%) other patients had drainage of abscess and no appendectomy. On the seventh day all the 19 (100\%) patients, and on the eighth day 4 (66.67\%) patients had appendectomy. The other $2(33.33 \%)$ patients on the eighth day had failed attempt of appendectomy and abscess drainage alone was done.

Two patients operated on $12^{\text {th }}$ and $15^{\text {th }}$ day had advanced adhesion and abscess was not present either. So, the wound was just closed. Both had given misleading history of duration of pain of 4 and 5 days. Initial pain in the epigastric region was attributed to acid peptic disorder and treated by local practitioner following which the pain temporarily subsided. After the incompatible operative finding, when history was reviewed, the patients were found to have deliberately dismissed the previous pain attributing it to different and unrelated entity. Their attention to appendix was gained after recurrence of pain and ultrasound of abdomen.

From ninth day onward, threshold for appendectomy increased and lesser procedure like extra-peritoneal abscess drainage. One patient was attempted for appendectomy on the $10^{\text {th }}$ day, but only abscess drainage was possible. Appendectomy was abandoned because of injury to ileum.

\section{Complications}

No patient with appendectomy had significant complication. One patient (age 42 years), operated on the 10th day of pain, sustained ileal injury $(1.5 \mathrm{~cm}$ rent $)$. After drainage of abscess, the injury was inflicted due to sharp dissection while attempt was made to mobilize cecum in order to search for retrocaecal appendix; the rent was closed by 2-0 chromic catgut. A tube drain was placed and the wound closed. However, he developed feculent drain on the third postoperative day which never exceeded 250 ml per day and gradually stopped over 10-12 days. He was discharged in a week with the drain in place.

The drain was removed in two weeks. Record of wound condition was available for 116 patients. Among them surgical site infection (SSI) was documented in 21 (18.1\%) patients. It was 9.3\% (6 in 64) in presence of phlegmon and $28.8 \%$ (15 in 52) in presence abscess and perforation. All patients had superficial SSI except one who developed deep SSI. He was the one with maximum hospital stay of 8 
days. Mean operative time was $36.6 \pm 10.9$ (range: 20-95) minutes. Mean hospital stay after surgery was $3.6 \pm 1.5$ (range: $2-8$ ) days.

\section{Follow up}

No patient with appendectomy reported significant complication after discharge. However, four previously nonappendectomized patients presented with recurrent appendicitis. Three patients had abscess drainage and one had open-close. Of these 4 patients, appendectomy was done in one. In another one, there was a thick residual abscess behind cecum which was drained but appendectomy was not feasible owing to dense adhesion behind the cecum. However she was well when she visited for other reason about 2 years later. The other two patient's didnot turn up after advice for appendectomy. The patient with ileal injury had visited 5-6 months later for lower urinary tract infection but was well otherwise.

\section{DISCUSSION}

In presence of appendiceal mass surgery is compounded by inflammatory adhesion, increased tissue friability risking bowel injury, and doubt ofmalignancy. Arsad et al. found difficulty in localization of appendix in $41(46.6 \%)$, difficulty in adhesiolysis in $23(26.1 \%)$, minor trauma to bowel in $13(14.8 \%)$ and bleeding in $11(12.5 \%)$ patients [8]. The fact that the inflammatory adhesion escalates with time up to certain period is an established fact. So, the same appendectomy may be simple if performed very early or very difficult if attempted late. At times, the mass may raise doubt of malignancy and tempt for hemicolectomy [11]. The results of our study embraces experienced facts which guide us to perform appendectomy safely and confidently in patients who present with AM.

\section{Key factors for safe appendectomy}

Traditionally emergency appendectomy for acute appendicitis has been regarded as a domain of surgical trainee. However, when AM is concerned, a touch of experienced hand becomes imperative. Various studies showed that, with increasing experience, EA in an AM is feasible and appropriate [13-15]. Samuel et al favored EA in pediatric patients presenting with AM. Nine patients had symptoms of $5.7 \pm$ 0.4 days at presentation and were operated $4.2 \pm 1.8$ days after admission. Twenty five patients were operated after $6.2 \pm 1.1$ days of symptoms [4]. Bahram reported EA in patients of AM with symptoms of 4-12 days. However, there was difficulty in dissection in $3(7 \%)$ patients, serosal tear in ileum and cecum in $3(7 \%)$ patients, and appendix was difficulty to localize due to difficult adhesiolysis in $4(10 \%)$ of patients [3].

The operative difficulties escalates as the mass grows older. So timing is an important factor. However, this timing is not clear. A recent study by the current author suggested safe time limit, in experienced hand, to be up to $7^{\text {th }}$ day since onset of pain [12]. Similar fact has been shown by the present study. Two patients could have drainage of abscess without appendectomy on the $6^{\text {th }}$ day only during the early years of experience. An advantage of this timing is evident from the fact that by the $7^{\text {th }}$ day majority $(87.4 \%)$ of patients were served with definitive treatment and left few to be managed with lesser surgery without breaching safety.

This study does not entertain milder form of inflammation where adhesion is minimal and appendectomy can be possible anytime. 
Current discussion is focused on commonly encountered mass with established inflammatory adhesion often with presence of abscess. This time limit is intended to guide most young surgeons to reduce worry of potential difficulty in dissection and injury due to inflammatory adhesion encountered intra-operatively. However, some variation in timing with individual experience is natural, as a few safe appendectomy were accomplished safely on the eight day in this study also. So, experience of surgeon and safe timing seem to be important for safe appendectomy.

\section{Surgical technique and concern of malignancy}

In presence of mass one need to be very careful while doing any sharp dissection. The ileac injury in a patient in this series was inflicted by scissor. Patience and adherence to blunt dissection is key to gradual and safer progress of surgery. Sharp dissection should be avoided in close vicinity to bowel. When blunt dissection is difficult and anatomy is obscure, and malignancy cannot be excluded, decision should take into consideration of loco-regional experience of association with malignancy, especially of cecum.

Association of malignancy with appendicitis has been reported between 0-4\% [16]. In his study Kaya et al reported that no patient who had right hemicolectomy during ESI for AM proved to have malignancy [11]. We too have no experience of such association. So, we suggest for limited procedure when dissection is difficult to progress. Abscess if present should be drained.

\section{Avoiding unnecessary laparotomies}

There is no substitute for careful history and examination but, during routine busy practices, it is not unusual to shorten history and examination part which at times leads to missing of important information. The two patients had just open-close mainly because of misleading history. An important clue to doubt duration of pain could be characteristic of mass. Both the patients had relatively well defined and less tender mass. In the early stage, the mass is relatively less well defined and tenderer. So, when we get a patient with well-defined and less tender mass, if the history appears shorter, the patient should be inquired dedicatedly about any other recent pain which the patient might be neglecting. After these two cases in the early years of experience, other relatively older masses were saved from unnecessary laparotomies.

The fact that most patients in this study lake long term follow up constitutes a limitation. This is because we lake dedicated follow up protocol taking into consideration of patients' ignorance and inconvenience. Secondly, appendix was not routinely submitted for histopathological examination. The reason is financial constraint of patients and experience of unlikelihood of association with malignancy. Occasionally it was sent for histopathological examination but none reported malignancy.

\section{CONCLUSION}

With experience we have developed confidence that experience and clarity of safe time limit makes EA in AM predictably safe. Few other patients who present later and need surgical intervention may be more safely managed by limited procedure like drainage of abscess without precarious attempt of appendectomy. Careful interpretation of clinical features is important 
in avoiding unnecessary laparotomy in a few late presenters.

\section{ACKNOWLEDGEMENT}

None

\section{AUTHOR'S CONTRIBUTION}

RKP-general Concept, design and writing; USG-acquistion of data and Analysis; VKJacquistion of data and Analysis; STM-drafting and data analysis

SOURCE OF SUPPORT: No any financial support was sought.

CONFLICT OF INTEREST: There is no conflict of interest

\section{REFERENCES}

1. Ochsner AJ. The cause of diffuse peritonitis complicating appendicitis and its prevention. JAMA 1901; 26:1747-54.

2. Mann CV, Russel RCG, Williams NS. The vermiform appendix. In: Bailey \& Love's short practice of surgery; 22nd edn. Arnold: London; 1998. pp. 828-41.

3. Bahram MA. Evaluation of early surgical management of complicated appendicitis by appendicular mass. Int J Surg 2011; 9(1):1013.

4. Samuel M, Hosie G, Holmes K. Prospective evaluation of nonsurgical versus surgical management of appendiceal mass. J Pediatr Surg 2002; 37:882-6.

5. Ahmed I, Deakin D, Parsons SL. Appendix mass: do we know how to treat it? Ann R CollSurg Engl 2005; 87(3):191-5.

6. Meeks DW, Kao LS. Controversies in appendicitis. Surg Infect (Larchmt) 2008; 9(6):553-8.

7. Irfan $M$, Hogan AM, Gately $R$, et al. Management of the acute appendix mass: a survey of surgical practice. Ir Med J 2012; 105(9):303-5.

8. Arshad Malik, Aziz Laghari A, QasimMallah, AltafHussainTalpur K. Early appendicectomy in appendicular mass dA LIAQUAT University hospital experience. J Ayub Med Coll Abbottabad 2008; 20(1):70-2.

9. Jordan JS, Kovalcik PJ, Schwab CW. Appendicitis with a palpable mass. Ann Surg 1981; 193:227-9.

10. Oliak D, Yamini D, Udani VM, et al. Nonoperative management of perforated appendicitis without periappendiceal mass. Am J Surg 2000; 179:177-81.

11. Kaya B, Sana B, Eris C, Kutanis Rl. Immediate appendectomy for appendiceal mass. Turkish J Trauma Emerg Surg 2012; 18:71-4.

12. Pandit RK. Safe and Feasible Time Limit for EA in Appendiceal Mass. Kathmandu Univ Med J 2016; 55(3):210-4.

13. De U, Ghosh S. Acute appendicectomy for appendicular mass: a study of 87 patients. Ceylon Med J 2002; 47(4):117-8.

14. Khan AW, Sheikh SH, Rahman MA. Results of emergency appendectomy for appendicular mass. Mymensingh Med J 2007; 16(2):209-13.

15. Garg P, Dass BK, Bansal AR, Chitkara N. Comparative evaluation of conservative management versus early surgical intervention in appendicular mass-a clinical study. J Indian Med Assoc 1997; 95(6):179-80, 196.

16. Sah JN. Interval appendectomy, is it necessary? JSSN 2007; 10(3):34-46.

\section{Correspondence to:}

Dr. Rakesh Kumar Pandit

Associate Professor

Department of Surgery

Janaki Medical College Teaching Hospital,

Ramdaiya

Email: rakeshkp1@yahoo.com 